\title{
Development of an OER Financial Accounting Text at Athabasca University and Implications for the Broader Post-Secondary Community
}

\author{
David Annand \\ Faculty of Business, Athabasca University, Athabasca, Canada \\ Email: davida@athabascau.ca
}

Received 10 July 2014; revised 20 August 2014; accepted 6 September 2014

Copyright (c) 2014 by author and Scientific Research Publishing Inc.

This work is licensed under the Creative Commons Attribution International License (CC BY). http://creativecommons.org/licenses/by/4.0/

\section{(c) (i) Open Access}

\begin{abstract}
The development of an introductory financial accounting text as an open educational resource (OER) is described and grounded in the literature. Based on these experiences, the concepts of openness and collaboration suggested in the literature are critiqued. Attributes contributing to financial sustainability of the project are discussed within the particular institutional environment and extended to the post-secondary community in general.
\end{abstract}

\section{Keywords}

Open Educational Resources, Open Textbooks, Electronic Textbooks, Economics of OER

\section{Introduction}

The Cape Town Open Education Declaration [1] proclaimed that a global open learning revolution is underway. One of the more remarkable developments within this open learning movement has been the growing use of open educational resources (OER) as a means to freely share, adapt, combine, extract, and generally propagate knowledge in formal and non-formal settings.

Butcher [2] stated that “.... an OER is simply an educational resource that incorporates a licence that facilitates reuse - and potentially adaptation — without first requesting permission from the copyright holder” (p. 34). He also highlighted important differences between OER and related concepts. First, OER are not synonymous with open learning. The latter assumes not only the use of OER as instructional material, but also the “.... systematic analysis of assessment and accreditation systems, student support, curriculum frameworks, mechanisms to rec- 
ognize prior learning, and so on, in order to determine the extent to which they enhance or impede openness" (p. 6). Second, Butcher suggested that OER are not synonymous with, but are rather subsumed by, resource-based learning. The latter uses diverse media and diminishes the transmission model characterizing face-to-face learning. As he stated, resource-based learning “... involves various forms of student support, for example, tutorials, peer group discussion, or practical work” (p. 20). Third, OER are not synonymous with open publishing. Open publishing refers freely-accessible scholarly publications and research. OER specifically denote open access to teaching and learning materials, though scholarly articles can be incorporated into OER learning materials for pedagogic purposes. Lastly, OER are not the same as online learning. An essential difference is that OER are also generally available in print, or at least on a print-on-demand basis. As such, OER can be used in a wide variety of delivery modes (p. 34).

This narrower definition of OER is used herein. It refers to the process of creating educational resources that are freely-available and adaptable, but limited to a formal learning context. Within these specifications, the development of an introductory financial accounting text as an OER at Athabasca University is described below. Based on these experiences, concepts of OER production processes as discussed in the literature are critiqued.

\section{Description of the OER Project's Context}

Athabasca University is located in Alberta, Canada. Since its formation in the 1970s as Alberta's fourth publicly-funded university, its mission has been to reduce barriers that traditionally restrict access to university-level education for adults in Alberta, in Canada, and throughout the world. To accomplish this, the institution has adopted open access policies in its undergraduate courses-for instance, offering courses almost exclusively by distance or online education; admitting any adult regardless of prior education; arranging comprehensive transfer credit arrangements with other educational institutions; and pioneering work in prior, non-formal learning assessment for university credit. The University offers undergraduate programs in humanities, social sciences, science, business, and nursing, and graduate programs in business, distance education, health studies, architecture, and integrated studies. Online graduate courses offered by the University are generally cohort-based, meaning they have fixed start and end dates. Students in each cohort move through a course at the same pace. This allows a greater degree of student-to-student interaction but reduces flexibility in terms of self-pacing.

Undergraduate courses, on the other hand, provide students with greater freedom. Students can start "individualized study" courses at any time during the year and can complete them at any time within a six-month contract period. These features allow Athabasca University undergraduate students, most of whom have work, family, and other obligations, to complete university courses at their own pace. The Faculty of Business offers cohort-based graduate and individualized study undergraduate business degrees. Courses within these programs account for about $1 / 3$ of the University's 45,000 total course registrations each year.

The individualized nature of undergraduate courses requires particular attention to instructional design. Because of the self-paced nature of these courses, students need to be provided with additional resources and assistance. The University spends a considerable amount of time and financial resources preparing course materials. A course team generally consists of a contracted subject matter expert (SME), the course coordinator (a full-time faculty member, who may also act as SME) an editor/instructional designer, copyright officer, and instructional media technologist. Still, a majority of undergraduate courses rely on traditional print-based, commerciallypublished textbooks as their primary educational resource. These "wrap-around" courses supplement textbooks with additional learning resources and detailed study guides to assist students.

\section{Description of the OER Project}

This paper describes the development of an OER-based accounting text used in an introductory-level financial accounting course offered by the Faculty of Business. As in most other post-secondary business programs, the course is required and heavily subscribed. It is consistently ranked as one of the top three courses at the institution in terms of enrolments. I was the faculty member responsible for this course from 1989 to 2003. During this time, there were about 1,000 course registrations per year in the course.

Initially, two editions of a popular textbook were purchased from a Canadian publisher and used in the course from 1989 to 2000. For several reasons, the publisher decided not to produce a third edition and the copyright reverted to the author in the mid-1990s. I approached the author about revising the text, then publishing it inhouse to use in the introductory financial accounting course. The major motivation for this was the potential to 
reduce costs to the institution. The University provides all instructional material including textbooks to students as part of their course fees. Any reduction in material costs would therefore translate directly into cost savings for the institution.

At the time, the University could purchase the text for about Cdn \$55. Publishing the paper-based text inhouse reduced variable production costs to about $\$ 30$ per text. Projected savings were estimated to be about $\$ 75,000$ over the estimated three-year life of the text before revision would be necessary. ${ }^{1}$ An estimated $\$ 55,000$ of one-time fixed production costs was needed to convert, update, and edit the revised third edition. As a result of the estimated $\$ 20,000$ cost savings in the first three-year life cycle alone, the University committed funds and staff to the conversion process. This included a graphic designer, a digital media technologist, an editor, and me as primary author.

The third edition was published by Athabasca University Press in 1999. Copyright remained with the original author and there was no attempt to make the finished product available as an OER. However, a beneficial byproduct of this process was that Athabasca University created and retained the digital files for the third edition of the text and solutions manual (approximately 1,400 pages in all), and also obtained the right to distribute this instructional material in any medium to its students. As a result, and while the paper-based textbook was being printed, the text was converted to e-book ${ }^{2}$ (.pdf) format using Adobe Acrobat Professional ${ }^{\circledR}$. Annand [3] described the conversion process, the results of a related comparative media study, and the cost comparisons of the e-book versus printed versions of the material.

The printed text and e-book versions were used in the introductory financial accounting course from 2000 to 2003, until a new faculty member took over the course and replaced the text with one purchased from a commercial publisher. Meanwhile, the digital files of the third edition text were stored on an Athabasca University server for over a decade.

During a 2012 sabbatical, I began to update and extensively revise the digital files of the third-edition with a view to creating a relatively complete fourth edition of the introductory financial accounting text as an OER. There were several factors that made this an attractive OER project:

a. Introductory financial accounting is a staple of postsecondary business programs worldwide so the potential market for adoption was large;

b. In 2010, Canada adopted International Financial Accounting Standards (IFRS). These guide development of financial statements in at least some situations (e.g., publicly traded companies) in a majority of nations. In addition, US generally accepted accounting principles will likely converge with IFRS in 2015. Thus the accounting principles to be embedded in the text were applicable to a large and growing number of countries;

c. There are few, if any, comprehensive introductory financial accounting texts available as OER.

The current round of the revision process was completed in 2014. Like the third edition, the fourth-edition material was also converted to e-book format. Unlike the third edition, the copyright holder agreed to license the printed and e-book versions of the 2014 text under a CC-BY-SA-NC license. ${ }^{3}$

From an economic standpoint, the incremental costs to the University of producing the OER text were low because of the pre-existing digital files of the third edition. Production of instructional materials by faculty is recognized as valid scholarly and research activity by the institution. The necessary writing and revising was done during my sabbatical, then as part of my regular duties. Because the material was to be used in an actual course, it was subjected to the normal quality assurance processes of the Faculty of Business. The manuscript was reviewed by another accounting professor and a professional editor.

The fourth edition text and solutions manual material files have been submitted in .docx and .pdf formats to several OER repositories (ocw.athabascau.ca; MERLOT; B.C. Open Textbook Project) for review, use, and adaptation under the (non-commercial) terms of the license. At present at Athabasca University, the OER text material is being incorporated into a new version of the introductory financial accounting course. As with the original project, potential cost savings to Athabasca University are significant because all instructional material continues to be provided to students as part of tuition fees.

In a related development, the University, the copyright holder, and a third-party online learning software de-

${ }^{1}(\$ 55-\$ 30) \times 1,000$ registrations per year $\times 3$ years $=\$ 75,000$.

${ }^{2}$ An e-book is defined as a printed book that is made available in a digital format to be read onscreen or downloaded to a portable electronic device.

${ }^{3}$ Re-use, adaptation, and dissemination of derivatives require attribution to the original authors. Production of only non-commercial works is permitted. 
veloper have entered into agreements whereby the software developer will convert the text to .html format and link this to a relatively sophisticated, commercially-hosted database. Algorithmically generated problems and extensive tailored feedback will be coupled with individualized tracking of student progress and performance.

The costs of purchasing a commercially-available text and ancillary material has risen to about $\$ 180$ per registration in 2014, and yearly enrolments in the introductory financial accounting course have increased to 1,700 students. Under the terms of the commercial agreement, the University will be charged about $\$ 70$ by the software developer for each student registration to recover the costs of online, enhanced student evaluation and feedback, and pay royalties to the copyright holder. Even at this, the potential cost saving to the University is about $\$ 187,000$ per year. ${ }^{4}$ The package will also be marketed commercially by the software developer to other post-secondary institutions.

Under this model, the value of the traditional "education content" of the text is zero, because the text and selected solutions will continue to be offered as freely-available OER. It is as yet unknown whether other institutions and their faculty will consider the approximately $\$ 70$ fee for the additional online review and feedback component a reasonable value proposition. They may opt for the basic model: a freely-available OER text in ebook format (or about $\$ 30$ as a print-on-demand textbook).

\section{Is this Educational Resource Actually “Open”?}

Given these commercial arrangements and some of the features of the OER text, the question arises as to whether this material is truly "open". This question can be usefully addressed using the "four Rs" of openness proposed by Hilton, Wiley, Stein, and Johnson [4]. First, is it reusable? Can learners (and instructors) freely use some or all of the text for their own purposes? Second, can the resource be redistributed to others by these learners and instructors? Third, can it be revised - for instance, adapted or translated to other cultures and languages? Fourth, can it be remixed so that parts of it can be combined with other works to create a new OER?

The project appears to meet the criteria. Despite the creation of ancillary online assessments by the software developer, the OER text and selected solutions are still available and adaptable under the terms of their Creative Commons licenses. One caveat is that providing the material in only .pdf and .docx (and not .html, for example) formats may limit adoption. Overall, though, the text does seem to meet the criteria for openness proposed by Hilton et al. However, they also pose technical criteria that enable openness-the ALMS analysis: access to editing tools whereby only a reasonable level of skill is necessary to change or adapt the material in a meaningful way using source files. Again with the case at hand, these criteria appear to be met, assuming that MS Word and Adobe Acrobat are ubiquitous and easy enough for others to revise and adapt the material desired. Indeed, making the OER available as a downloadable file reduces the needs for bandwidth and reliable Internet connectivity. This may actually increase the 'openness' of the material. Bossu \& Tynan [5] noted that this is often an important consideration in developing countries.

\section{Implications for OER Development}

The development of OER has often been characterized as a collaborative activity. For instance, Downes [6] suggested that the continued use of OER will likely require the active collaboration of "co-producers" (in particular learners) to enhance and improve the material. Amiel [7] also noted that one initial attraction of OER was the perceived ability of several authors to collaborate. However, both Amiel [7], and Bossu and Tynan [5] opined that collaboration has often failed to materialize, and that production of OER that rival commerciallyavailable textbooks in terms of content coverage has been hampered. Historically, faculty members often do not have the time to collaborate or otherwise adapt OER material due to heavy workloads and lack of extrinsic rewards for this activity. They prefer to use a relatively complete work that requires little adaptation and avoids the need for managing even a small collaborative project staffed by volunteers. Also, many academics are not willing to deal with the potential licensing conflicts that can occur when constituent OER parts are combined into a larger product. Butcher [2] noted that these factors, “... have left many academic staff with few or no opportunities to venture into the OER movement” (p. 261).

To date, my experiences substantiate these suggestions that the case for collaboration of OER may be overemphasized, at least in a formal learning environment. The project described above was largely the result of various individuals' efforts operating in a linear fashion over almost two decades (the original author's contribu-

${ }^{4}(\$ 180-70) \times 1,700$ yearly enrolments $=\$ 187,000$. 
tions, then mine, then revisions suggested by a fellow academic). Collaboration in terms of co-production of the text was minimal.

Despite the ability to freely-adapt the material, the greatest interest at present from outside the University has been from accounting educators who are primarily interested in replacing an expensive textbook with a free, adequate alternative. They are motivated by a philanthropic desire to reduce costs to students. Lacking incentives from their institutions like releases time, recognition, and production assistance to produce or even adapt relatively comprehensive OER themselves, these academics seem to desire a fully-formed resource, complete with adequate problem material and solutions. In cases where adaptation of the OER text is being considered by others, initial indications are that these will take the forms of either translation into another language or adoption of local terminology to describe the more general and widely-accepted underlying accounting concepts. This desire to adopt the material as is, or translate it relatively verbatim, may be a function of the nature of introductory financial accounting itself, particularly its generally prescriptive nature, the well-established and entrenched practice of double-entry bookkeeping underlying the content, the need to cover a large amount of material to meet learning requirements of professional accounting organizations or governments, and the growing ubiquity of IFRS-based generally accepted accounting principles.

The main attraction of the OER text appears to be the availability of a relatively complete resource. The fact that this is capable of being somewhat altered to accommodate variations in local custom, language, and terminology, and to use some local case studies and examples, may suffice for adaptation and use of the text in many countries. These phenomena appear to be at odds with the extant literature, which generally promotes the possibilities of collaboration, or assumes that collaboration will be a primary characteristic of OER development. Based on the limited experiences to date with the use of the material described herein, direct, unaltered replacement of commercially-available material with an adequate, relatively complete alternative seems to be the desire of most adopters. As de Langen [8] noted, the motives and interest of OER users requires further study.

\section{Conclusions}

Several factors have been important for the successful development of the OER accounting text described above. First, Athabasca University benefits financially from the development and use of OER. Operating costs are lowered when OER is adopted because the University's tuition fees include the costs of all instructional materials. These potential cost savings enabled the initial conversion in the 1990s of a commercially-available accounting text to one produced in-house, and thence the revision and conversion of the materials to OER as described above. Second, developing instructional material is recognized as valid scholarly activity for the University's faculty members. As a result, institutional needs (lower production costs) have been aligned with individual faculty incentives. These relatively unusual circumstances have enabled the OER project described herein to succeed, though as with most groundbreaking activities, more as a result of individual incentive than proactive management. Despite the demonstrable cost savings of OER development and adoption, the University has been slow to encourage similar, large-scale OER projects. The idea is gaining traction, however (Ives and Pringle, [9]).

There have been other necessary developments. Over the last decade, licensing of OER material has been simplified and standardized through the use of Creative Commons and similar protocols. Also, the ability to produce and access OER from virtually anywhere in the world has removed much of the economic advantage enjoyed in the past by commercial publishers. With advances in technology and changes to the way in which education is funded (for instance, including cost of instructional materials in tuition fees of all post-secondary institutions), the process of producing less-expensive, high quality instructional material can be gradually shifted away from the commercial realm to the academy. This augers well for OER production in the future. As the project described herein demonstrates, it could point to a sustainable means to increase the demand for and supply of high-quality OER in post-secondary education.

\section{References}

[1] Cape Town Open Education Declaration (2008) www.capetowndeclaration.org/read-the-declaration

[2] Butcher, N. (2011) A Basic Guide to Open Educational Resources (OER). Commonwealth of Learning, Vancouver. http://www.col.org/PublicationDocuments/Basic-Guide-To-OER.pdf

[3] Annand, D. (2008) Learning Efficacy and Cost-Effectiveness of Print versus E-Book Instructional Material in an In- 
troductory Financial Accounting Course. Journal of Interactive Online Learning, 7. http://www.ncolr.org/issues/jiol/v7/n2

[4] Hilton, J., Wiley, D., Stein, J. and Johnson, A. (2010) The Four 'R's of Openness and ALMS Analysis: Frameworks for Open Educational Resources. Open Learning, 25, 37-44. http://dx.doi.org/10.1080/02680510903482132

[5] Bossu, C. and Tynan, B. (2011) OER: New Media on the Learning Landscape. On the Horizon, 19, $259-267$. http://dx.doi.org/10.1108/10748121111179385

[6] Downes, S. (2007) Models for Sustainable Open Educational Resources. Interdisciplinary Journal of Knowledge and Learning Objects, 3, 29-44.

[7] Amiel, T. (2013) Identifying Barriers to the Remix of Translated Open Educational Resources. International Review of Research in Open and Distance Learning, 14, 126-144. http://www.irrodl.org/index.php/irrodl/article/view/1351

[8] De Langen, F. (2013) Strategies for Sustainable Business Models for Open Educational Resources. International Review of Research in Open and Distance Learning, 14. http://www.irrodl.org/index.php/irrodl/article/view/1533/2485

[9] Ives, C. and Pringle, M. (2013) Moving to Open Educational Resources at Athabasca University: A Case Study. International Review of Research in Open and Distance Learning, 14.

http://www.irrodl.org/index.php/irrodl/article/view/1534/2486 
Scientific Research Publishing (SCIRP) is one of the largest Open Access journal publishers. It is currently publishing more than 200 open access, online, peer-reviewed journals covering a wide range of academic disciplines. SCIRP serves the worldwide academic communities and contributes to the progress and application of science with its publication.

Other selected journals from SCIRP are listed as below. Submit your manuscript to us via either submit@scirp.org or Online Submission Portal.
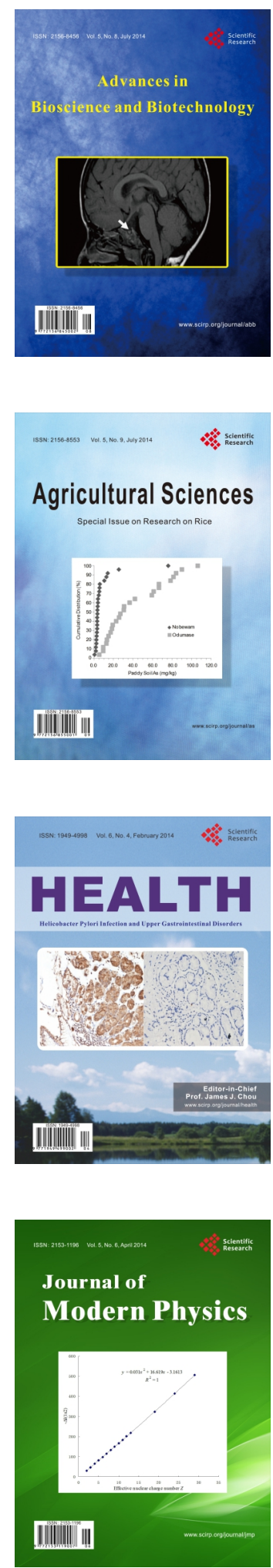
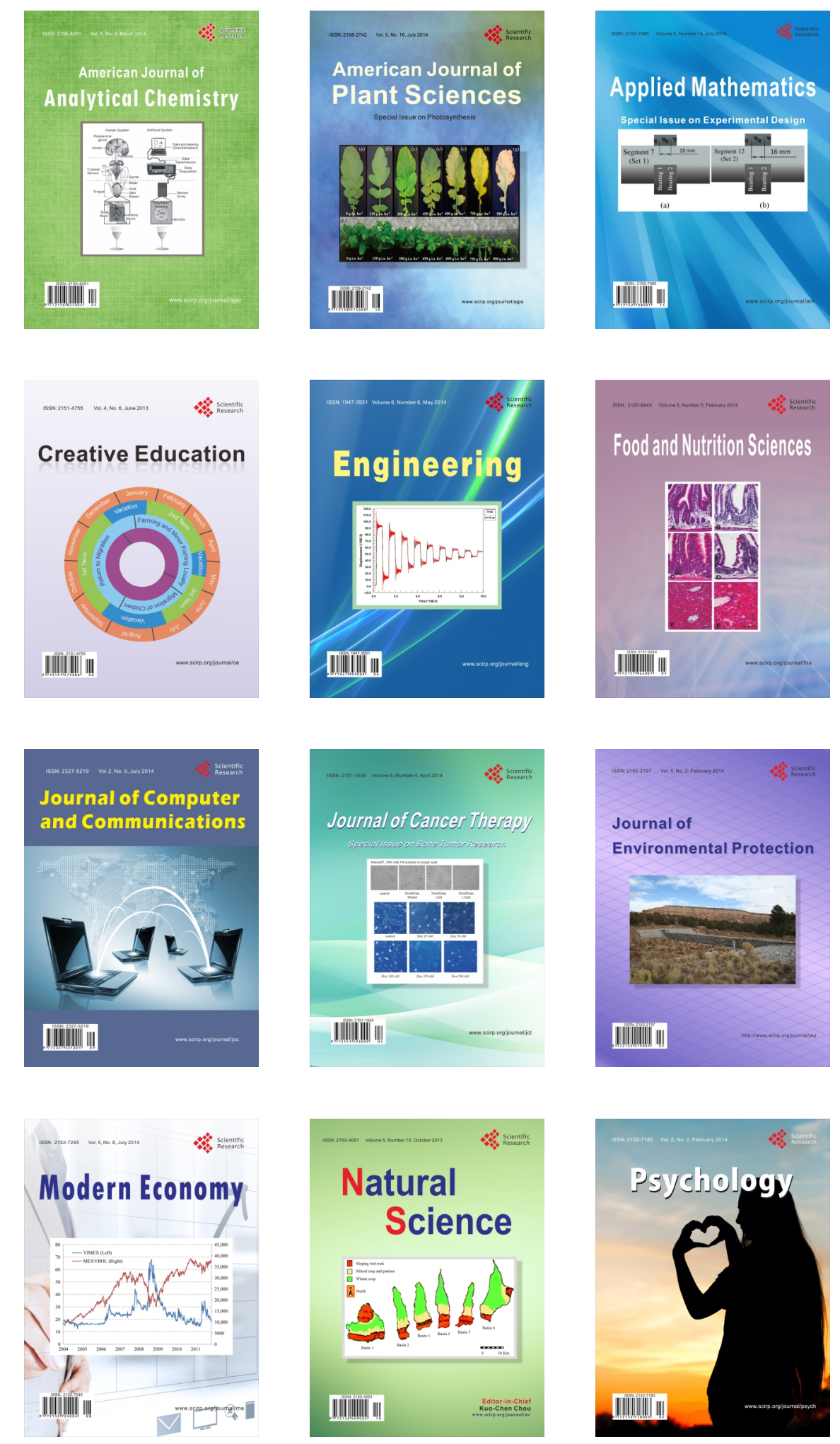